\title{
Tumstatin induces apoptosis mediated by Fas signaling pathway in oral squamous cell carcinoma SCC-VII cells
}

\author{
JEON HWANG-BO* , JONG-HWA PARK ${ }^{*}$ and IN SIK CHUNG \\ Department of Genetic Engineering and Graduate School of Biotechnology, \\ Kyung Hee University, Yongin, Gyeonggi 446-701, Republic of Korea
}

Received August 14, 2014; Accepted May 7, 2015

DOI: $10.3892 / 01.2015 .3261$

\begin{abstract}
Oral squamous cell carcinoma is a cancer originating in the tissues lining the mouth and lips. The present study investigated the effects of recombinant tumstatin, an anti-angiogenic agent with distinct antitumor activity, on oral squamous cell carcinoma SCC-VII cells. Apoptosis was characterized by YO-PRO-1 staining, sub-G1 population, and DNA fragmentation analysis. Apoptotic mechanism of tumstatin was also investigated. The antitumor activity of tumstatin was further evaluated using an SCC-VII animal model. Recombinant tumstatin was found to decrease the viability of SCC-VII cells in a dose-dependent manner. The number of cells stained with the apoptotic marker YO-PRO-1, the sub-G1 cell population and the level of apoptotic DNA fragmentation increased in the SCC-VII cells following treatment with recombinant tumstatin. In addition, recombinant tumstatin treatment increased the expression of the Fas gene at the transcript and protein levels, and the inhibition of cell viability by recombinant tumstatin was suppressed by a neutralizing anti-Fas antibody. Furthermore, treatment with recombinant tumstatin decreased the volume and weight of tumors in $\mathrm{C} 3 \mathrm{H} / \mathrm{HeJ}$ mice implanted with SCC-VII cells. In conclusion, the results indicated that tumstatin induced apoptosis that is mediated by the Fas signaling pathway in SCC-VII cells and inhibited tumor growth in an SCC-VII animal model.
\end{abstract}

\section{Introduction}

Oral cancer, a type of head and neck cancer, refers to cancerous tissues growing in the oral cavity and may arise as a primary lesion originating in any of the mouth tissues (1).

Correspondence to: Professor In Sik Chung, Department of Genetic Engineering and Graduate School of Biotechnology, Kyung Hee University, 1732 Deogyeong-daero, Yongin, Gyeonggi 446-701, Republic of Korea

E-mail: ischung@khu.ac.kr

*Contributed equally

Key words: oral squamous cell carcinoma, tumstatin, apoptosis, Fas, antitumor activity
Oral cancer may also occur due to metastasis from a distant site of origin or by extension from a neighboring anatomical structure. Approximately $90 \%$ of oral cancer cases are squamous cell carcinomas that originate in tissues lining the mouth and lips (2). Squamous cell carcinoma is managed by surgery, radiotherapy and chemotherapy, alone or in combination; however, the five-year survival rate is poor, at $~ 50 \%$ (2). Therefore, novel diagnostic and therapeutic methods to detect squamous cell carcinomas at an early stage and increase the survival rate are urgently required.

Apoptosis, a strictly controlled mechanism of cell death, is triggered by internal or external signals. This process is crucial in the development and maintenance of multicellular organisms through the elimination of superfluous or unwanted cells (3). Cells that are undergoing apoptosis exhibit characteristic morphological and functional changes, including reduction of the cell and nucleus sizes, plasma membrane blebbing, chromatin condensation and DNA fragmentation (4). The induction of apoptosis in malignant cells is a potential target for the development of novel antitumor drugs $(5,6)$. Tumor-induced angiogenesis, a process leading to the development of new blood vessels from pre-existing vessels, is critical in the development and dissemination of the majority of malignant tumors (7). Therefore, the development of antitumor drugs that possess anti-angiogenic activity, to inhibit tumor angiogenesis, and antitumor activity, to induce apoptosis in cancer cells, may be a valuable strategy in cancer treatment.

Tumstatin, a 28-kDa C-terminal globular noncollagenous domain of the $\alpha 3$ chain of type IV collagen, is an antiangiogenic agent with distinct antitumor activity $(8,9)$. Previous studies revealed that tumstatin inhibits tumor growth in several tumor models of malignant melanoma and glioma (10-12) and has been suggested as a potential candidate to inhibit angiogenesis and tumor growth in head and neck cancer models. In addition, tumstatin has been demonstrated to delay primary tumor growth and lymph node metastasis in an orthotopic oral squamous carcinoma AT-84 animal model (13); however, the apoptotic mechanism of tumstatin in oral squamous carcinoma cells has not been fully investigated. In the current study, the activity of tumstatin in mouse squamous cell carcinoma SCC-VII cells and the underlying apoptotic mechanism were investigated. In addition, the antitumor activity of tumstatin was evaluated in an SCC-VII animal model. 


\section{Materials and methods}

Cell culture. Mouse squamous cell carcinoma SCC-VII cells were provided by Dr Han-Sin Chung (Samsung Medical Center, Seoul, Korea). SCC-VII cells were grown at $37^{\circ} \mathrm{C}$ in an atmosphere of 5\% $\mathrm{CO}_{2}$ in RPMI-1640 medium (Thermo Fisher Scientific Inc., Waltham, MA, USA) supplemented with $10 \%(\mathrm{v} / \mathrm{v})$ fetal bovine serum (FBS; Thermo Fisher Scientific Inc.) and $1 \%(\mathrm{v} / \mathrm{v})$ penicillin-streptomycin (Thermo Fisher Scientific Inc.). Stably transfected Drosophila melanogaster Schneider 2 (S2) cells expressing recombinant tumstatin (14) were grown at $27^{\circ} \mathrm{C}$ in HyClone SFX-insect medium (Thermo Fisher Scientific Inc.) containing $300 \mu \mathrm{g} / \mathrm{ml}$ hygromycin B (Duchefa Biochemie, Haarlem, Netherlands). The study was approved by the Ethics Committee of Kyung Hee University (Yongin, Korea).

Cytotoxicity assay. The cytotoxicity of recombinant tumstatin was measured using a 3-(4,5-dimethylthiazol-2-yl)-2,5-diphenyltetrazolium bromide (MTT; Sigma-Aldrich, St. Louis, MO, USA) colorimetric assay. SCC-VII cells were seeded into 6-well plates (Nunc A/S, Roskilde, Denmark) at a density of $1 \times 10^{5}$ cells/well in $2 \mathrm{ml}$ RPMI-1640 supplemented with $10 \% \mathrm{FBS}$, and incubated for $24 \mathrm{~h}$. The cells were then treated with RPMI-1640 containing 2\% FBS and various concentrations of recombinant tumstatin (1, 5, 10, 20 and $30 \mu \mathrm{g} / \mathrm{ml}$ ). An equal volume of $30 \mathrm{mM}$ HEPES (Polysciences, Inc., Warrington, PA, USA) was used as a negative control. After a 24-h incubation period, $50 \mu \mathrm{l}$ MTT [5 $\mu \mathrm{g} / \mathrm{ml}$ in phosphate-buffered saline (PBS)] was added to each well, and the cells were further incubated at $37^{\circ} \mathrm{C}$ for $2 \mathrm{~h}$. Subsequently, the medium was replaced with $100 \mu \mathrm{l}$ of dimethyl sulfoxide (Duchefa Biochemie) and the plate was incubated for $5 \mathrm{~min}$ prior to measuring the optical density (OD) at $550 \mathrm{~nm}$ using an EL800 Universal Microplate Reader (BioTek Instruments Inc., Winooski, VT, USA). Cell viability was calculated as the percentage of viable cells in the recombinant tumstatin-treated group relative to the control group, according to the following equation: Cell viability $(\%)=$ $\left[\left(\mathrm{OD}_{\text {Recombinant tumstatin }}-\mathrm{OD}_{\text {Blank }}\right) /\left(\mathrm{OD}_{\text {Control }}-\mathrm{OD}_{\text {Blank }}\right)\right]$ x 100.

Confocal microscopy. SCC-VII cells were seeded into 6 -well plates (Nunc A/S) at a density of $1 \times 10^{5}$ cells/well and incubated for $24 \mathrm{~h}$. The cells were treated with RPMI-1640 containing $2 \%$ FBS and various concentrations of recombinant tumstatin $(1,5,10,20$ and $30 \mu \mathrm{g} / \mathrm{ml})$ for $24 \mathrm{~h}$. Next, the cells were harvested, washed with ice-cold PBS buffer, resuspended in $20 \mu \mathrm{l}$ PBS buffer and stained with $0.2 \mu \mathrm{M}$ YO-PRO-1 (Molecular Probes Inc., Eugene, OR, USA) for 20 min on ice in the dark. The fluorescence of the stained cells was imaged under $\mathrm{x} 40$ objective magnification using a confocal laser scanning microscope (LSM 510 Meta; Carl Zeiss, Oberkochen, Germany) with a $488 \mathrm{~nm}$ argon laser, $543 \mathrm{~nm}$ HeNe laser and $633 \mathrm{~nm}$ HeNe laser.

Cell cycle analysis. SCC-VII cells were seeded into $75 \mathrm{~cm}^{2}$ tissue culture flasks (T-75 flask; Nunc A/S) at a density of $1 \times 10^{6}$ cells/flask and incubated for $24 \mathrm{~h}$ in RPMI-1640 medium containing $2 \%$ FBS. Following treatment with various concentrations of recombinant tumstatin $(1,5,10,20$ and $30 \mu \mathrm{g} / \mathrm{ml})$ for $24 \mathrm{~h}$, the cells were washed twice with ice-cold PBS buffer, and cell pellets were fixed in $70 \%(\mathrm{v} / \mathrm{v})$ cold ethanol overnight at $-20^{\circ} \mathrm{C}$. The fixed cells were centrifuged at $700 \mathrm{x}$ for $5 \mathrm{~min}$, washed, resuspended in $100 \mu \mathrm{l}$ PBS containing $1 \mathrm{mM}$ RNase A (Qiagen, Hilden, Germany) and then incubated for $30 \mathrm{~min}$ at $37^{\circ} \mathrm{C}$. Next, the cells were stained by incubation with $400 \mu \mathrm{l}$ propidium iodide (PI; $50 \mu \mathrm{g} / \mathrm{ml}$; Sigma-Aldrich) for $30 \mathrm{~min}$ in the dark and subsequently filtered through a $40 \mu \mathrm{m}$ nylon mesh (BD Biosciences, San Jose, CA, USA). The DNA content of the stained cells was analyzed using a FACSVantage SE flow cytometry system and CellQuest program (BD Biosciences).

DNA fragmentation assay. SCC-VII cells were plated at a density of $1 \times 10^{6}$ cells/T-75 flask and cultured for $24 \mathrm{~h}$. The cells were treated with RPMI-1640 containing $2 \%$ FBS and $20 \mu \mathrm{g} / \mathrm{ml}$ recombinant tumstatin for 6, 12, 24 and $48 \mathrm{~h}$. Genomic DNA was prepared using a QIAamp DNA Mini Kit (Qiagen) according to the manufacturer's instructions. Next, the isolated genomic DNA samples were subjected to electrophoresis on a $1.8 \%$ agarose gel at $50 \mathrm{~V}$ for $1.5 \mathrm{~h}$. The gel was stained with ethidium bromide (EtBr; Sigma-Aldrich) and visualized using an ultraviolet (UV) transilluminator (Wealtech Corp., Reno, NV, USA).

Reverse transcription-polymerase chain reaction (RT-PCR). SCC-VII cells were plated at a density of $1 \times 10^{6}$ cells/T-75 flask and cultured for $24 \mathrm{~h}$. Next, the cells were treated with RPMI-1640 medium containing 2\% FBS and $20 \mu \mathrm{g} / \mathrm{ml}$ recombinant tumstatin for $12 \mathrm{~h}$. Total RNA was isolated using TRIzol reagent (Life Technologies, Carlsbad, CA, USA) according to the manufacturer's instructions. Total RNA (2 mg) was then treated with RNase-free DNase I (Life Technologies) and transcribed into cDNA using an ImProm- $\mathrm{II}^{\mathrm{TM}}$ Reverse Transcription System (Promega Corporation, Madison, WI, USA) in $20 \mathrm{ml}$ reaction mixtures containing oligo-dT primers according to the manufacturer's protocols. PCR was performed with $2 \mathrm{ml}$ cDNA and specific primers using an LA Taq DNA Polymerase kit (Takara Bio Inc., Shiga, Japan). The sense and antisense primers used were as follows: Fas sense, 5'-TGCTCAGAAGGATTATATCAAGGAG-3', and antisense, 5'-CGGGATGTATTTACTCAAGCTAAGA-3'; $\beta$-actin sense, 5'-AGAGAGGTATCCTGACCCTGAAGTA-3', and antisense, 5'-AGTCTAGACGAACATAGCACAGCTT-3'. The PCR program consisted of an initial denaturation at $94^{\circ} \mathrm{C}$ for $5 \mathrm{~min}$, followed by 30 cycles of $94^{\circ} \mathrm{C}$ for $1 \mathrm{~min}, 55^{\circ} \mathrm{C}$ for $1 \mathrm{~min}$ and $72^{\circ} \mathrm{C}$ for $1 \mathrm{~min}$, with a final extension at $72^{\circ} \mathrm{C}$ for $10 \mathrm{~min}$. Equal volumes of the PCR products were separated on $1 \%$ agarose gels and visualized under UV light after staining with EtBr. PCR products were quantified using the Image $\mathbf{J}$ program (National Institutes of Health, Bethesda, MD, USA).

Western blot analysis. SCC-VII cells were incubated in RPMI-1640 medium containing $2 \%$ FBS and $20 \mu \mathrm{g} / \mathrm{ml}$ recombinant tumstatin for $6,12,24$ and $48 \mathrm{~h}$ and then lysed with radioimmunoprecipitation assay buffer (Thermo Fisher Scientific Inc.) supplemented with a protease inhibitor cocktail (Roche, Basel, Switzerland). An RC/DC Bio-Rad assay kit (Bio-Rad Laboratories, Inc., Hercules, CA, USA) was used to determine the protein concentration, according to the manufacturer's instructions. Electrophoresis was then 
used to separate the protein samples on a $10 \%$ polyacrylamide-sodium dodecyl sulfate gel, and the samples were subsequently transferred onto a polyvinylidene fluoride membrane (Pall Corporation, Port Washington, NY, USA). The membranes were pre-incubated in blocking solution [5\% (w/v) skimmed milk in Tris-buffered saline containing $0.1 \%$ Tween-20] for $1 \mathrm{~h}$, incubated with a rabbit polyclonal antihuman Fas antibody (1:2,000 dilution in blocking solution) or mouse monoclonal anti-avian $\beta$-actin (cat. no. sc-7886 and sc-47778, respectively; Santa Cruz Biotechnology, Inc., Santa Cruz, CA, USA) overnight at $4^{\circ} \mathrm{C}$. Subsequently, the samples were probed with peroxidase-conjugated anti-rabbit or anti-mouse immunoglobulin $\mathrm{G}$ antibody (1:5,000 dilution in blocking solution; Santa Cruz Biotechnology, Inc.). An enhanced chemiluminescence western blotting detection reagent was applied to allow detection of the protein bands (GE Healthcare Life Sciences, Stockholm, Sweden).

Tumor growth in an in vivo SCC-VII animal model. A total of 18 five-week-old female $\mathrm{C} 3 \mathrm{H} / \mathrm{HeJ}$ mice with an average weight of $20 \mathrm{~g}$ (purchased from Orient Bio Inc., Seongnam, Korea) were quarantined in a specific pathogen-free environment, with access to water and food ad libitum and a $12 \mathrm{~h}$ light/ $12 \mathrm{~h}$ dark cycle. The mice were kept in an animal care facility accredited by the Kyung Hee University Institutional Animal Care and Use Committee. Animal care and experimental procedures adhered to the Kyung Hee University guidelines for the care and use of laboratory animals. To establish an in vivo SCC-VII animal model, $1 \times 10^{6}$ SCC-VII cells in $100 \mu 1$ PBS were subcutaneously injected into the right flank of the $\mathrm{C} 3 \mathrm{H} / \mathrm{HeJ}$ mice. After five days, when the tumors formed visible masses, the animals were divided into three groups, each containing six mice. Each group was treated at three-day intervals with a peritumoral injection of recombinant tumstatin $(2.5$ or $10 \mathrm{mg} / \mathrm{kg}$ in PBS) or PBS (control) over a period of nine days. All the mice were euthanized using $\mathrm{CO}_{2}, 14$ days after tumor inoculation and the tumors were excised and weighed. A caliper was used to determine the length and width of the tumors, and the tumor volume was calculated using the standard formula: length $\mathrm{x}$ width ${ }^{2} \times 0.5$ (15).

Statistical analysis. Data are presented as the mean \pm standard deviation (SD). Student's $t$-test was used to compare different data groups and all the data were analyzed using Microsoft Excel 2010 software (Microsoft Corporation, Redmond, WA, USA). $\mathrm{P}<0.05$ was considered to indicate a statistically significant difference.

\section{Results}

Recombinant tumstatin decreases the viability of SCC-VII cells. To evaluate the cytotoxic effect of recombinant tumstatin, SCC-VII cells were treated with various concentrations $(0,0.1,0.5,1,5,10,20$ and $30 \mu \mathrm{g} / \mathrm{ml})$ of recombinant tumstatin for $24 \mathrm{~h}$, and cell viabilities were evaluated by an MTT assay. Recombinant tumstatin decreased the viability of SCC-VII cells in a dose-dependent manner. Following treatment with $30 \mu \mathrm{g} / \mathrm{ml}$ recombinant tumstatin for $24 \mathrm{~h}$, the viability of SCC-VII cells decreased to $10 \%$ of that for untreated control

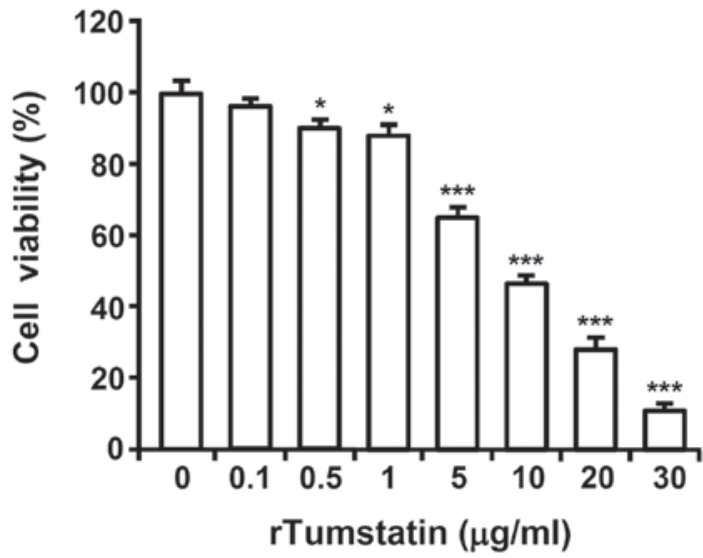

Figure 1. Effect of rTumstatin on the viability of SCC-VII cells. SCC-VII cells were treated with various concentrations $(0.1,0.5,1,5,10,20$ and $30 \mu \mathrm{g} / \mathrm{ml}$ ) of rTumstatin for $24 \mathrm{~h}$, and cell viability was determined by an MTT assay. Data are presented as the mean \pm standard deviation of three experiments. ${ }^{*} \mathrm{P}<0.05$ and ${ }^{* * *} \mathrm{P}<0.001$, vs. control group $(0 \mu \mathrm{g} / \mathrm{ml})$. rTumstatin, recombinant tumstatin.

cells $(\mathrm{P}=0.000026)$. The $50 \%$ inhibitory concentration value of recombinant tumstatin was $\sim 9 \mu \mathrm{g} / \mathrm{ml}$ (Fig. 1).

Recombinant tumstatin induces apoptosis in SCC-VII cells. To determine whether the cytotoxic effect of recombinant tumstatin was caused by apoptosis, recombinant tumstatin-treated SCC-VII cells were stained with the cell permeable green fluorescence dye, YO-PRO-1, as a marker of apoptosis and monitored under a confocal microscope (Fig. 2). Recombinant tumstatin increased the number of YO-PRO-1-stained cells in a dose-dependent manner. Cell cycle analysis was performed to determine the sub-G1 apoptotic population of recombinant tumstatin-treated SCC-VII cells. The cells were treated with various concentrations $(1$, $5,10,20$, and $30 \mu \mathrm{g} / \mathrm{ml})$ of recombinant tumstatin for $24 \mathrm{~h}$ and their DNA contents were analyzed by flow cytometry following PI staining. As shown in Fig. 3A, the number of cells in the sub-G1 population increased in a dose-dependent manner following treatment with recombinant tumstatin. After $24 \mathrm{~h}$ of incubation with recombinant tumstatin at a concentration of $1,5,10,20$ or $30 \mu \mathrm{g} / \mathrm{ml}$, the number of cells in the sub-G1 population increased to $0.37,0.51,3.13,15.65$ and $46.81 \%$ of total cells, respectively (Fig. 3B). The induction of apoptosis by recombinant tumstatin was further characterized by a DNA fragmentation assay. Genomic DNA was purified from SCC-VII cells following treatment with $20 \mu \mathrm{g} / \mathrm{ml}$ recombinant tumstatin for the indicated times $(6,12,24$ and $48 \mathrm{~h})$ and subjected to agarose gel electrophoresis to assess DNA fragmentation (Fig. 3C). DNA fragmentation was observed in recombinant tumstatin-treated cells and increased in a time-dependent manner. These results indicate that recombinant tumstatin induces apoptosis in SCC-VII cells.

The induction of apoptosis in SCC-VII cells by tumstatin is mediated by Fas. Expression of the Fas gene in recombinant tumstatin-treated SCC-VII cells was determined by RT-PCR (Fig. 4A). Total RNA samples were prepared from the SCC-VII cells following treatment with $20 \mu \mathrm{g} / \mathrm{ml}$ recombinant tumstatin for $12 \mathrm{~h}$. The level of Fas transcript was markedly 
rTumstatin $(\mu \mathrm{g} / \mathrm{ml})$
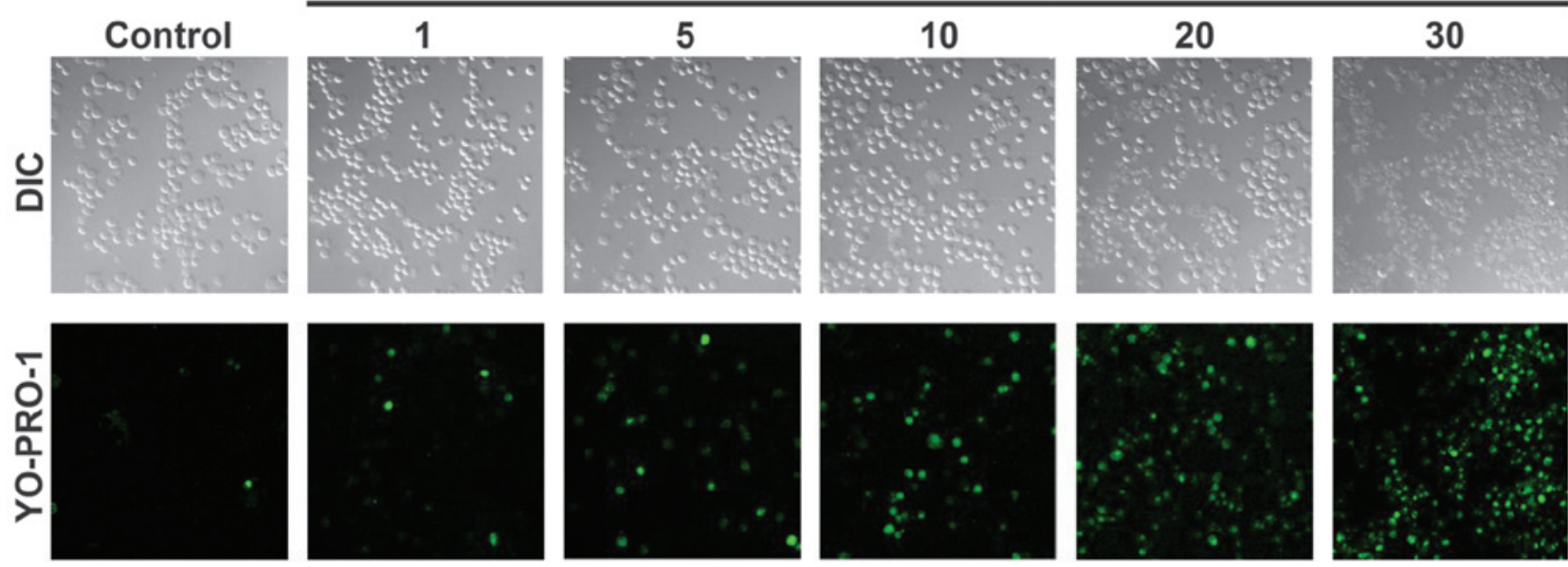

Figure 2. Analysis of apoptotic cells by staining with YO-PRO-1. SCC-VII cells were treated with various concentrations (1, 5, 10, 20, and 30 $\mu \mathrm{g} / \mathrm{ml})$ of rTumstatin for $24 \mathrm{~h}$ and stained with YO-PRO-1. Cells were imaged under $\mathrm{x} 40$ objective magnification using a confocal microscope. rTumstatin, recombinant tumstatin; DIC, differential interference contrast.

A

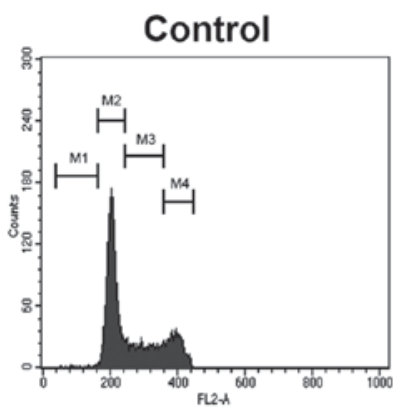

rTumstatin, $10 \mu \mathrm{g} / \mathrm{ml}$

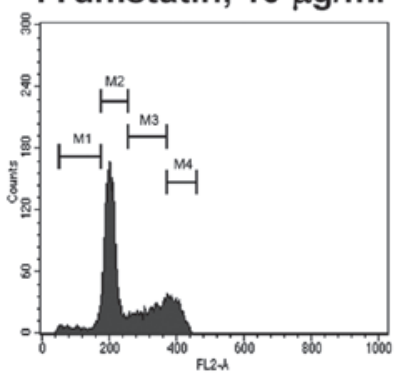

B

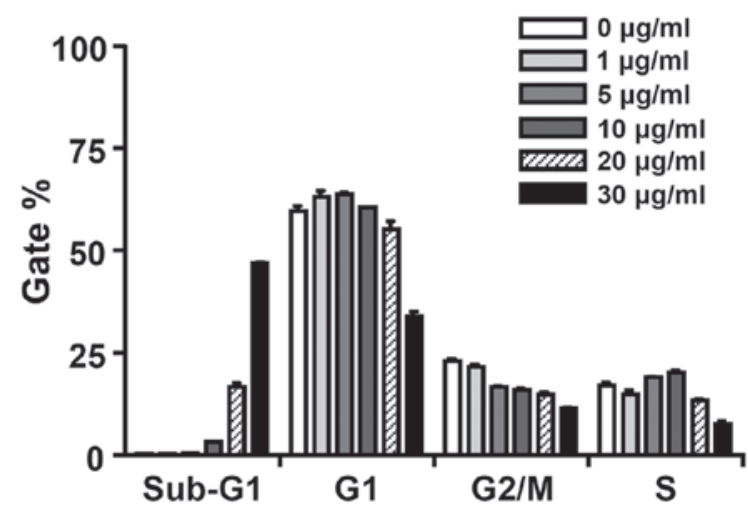

rTumstatin, $1 \mu \mathrm{g} / \mathrm{ml}$

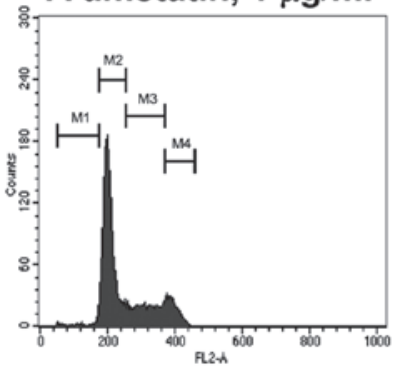

rTumstatin, $20 \mu \mathrm{g} / \mathrm{ml}$

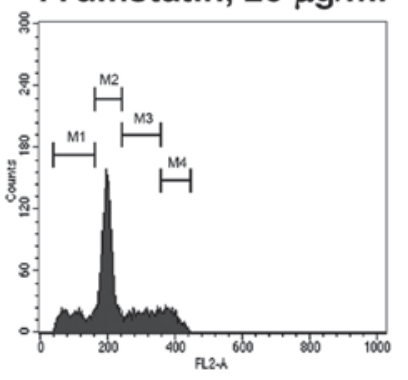

C

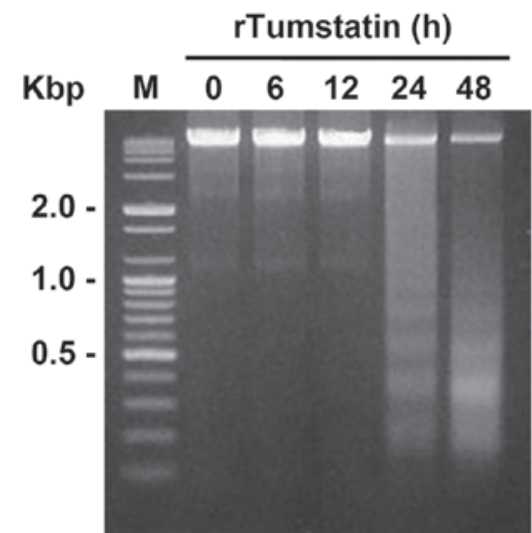

Figure 3. Flow cytometric analysis of sub-G1 cell populations and DNA fragmentation of rTumstatin-treated SCC-VII cells. (A) DNA content of SCCVII cells treated with different concentrations $(1,5,10,20$, and $30 \mu \mathrm{g} / \mathrm{ml})$ of rTumstatin for $24 \mathrm{~h}$, measured using a flow cytometer subsequent to staining with propidium iodide. (B) Cell cycle distribution data from three independent experiments, performed as described in (A). (C) DNA fragmentation of SCC-VII cells that were treated with $20 \mu \mathrm{g} / \mathrm{ml}$ recombinant tumstatin for the indicated times $(6,12,24$ and $48 \mathrm{~h})$ and analyzed by agarose gel electrophoresis. rTumstatin, recombinant tumstatin; M, 100 bp DNA ladder size marker. 
A

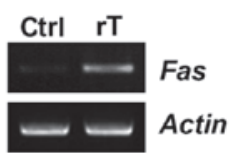

B

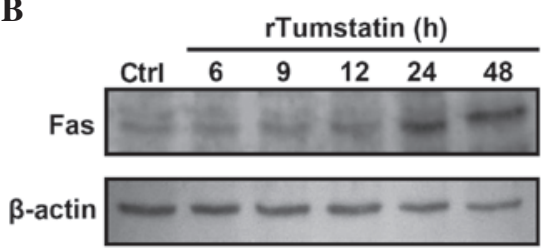

C

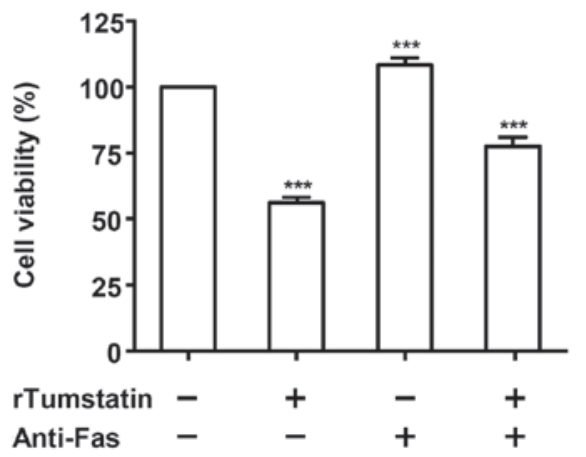

Figure 4. Effect of recombinant tumstatin on the expression of Fas. (A) Semi-quantitative reverse transcription-polymerase chain reaction was performed to determine the transcript expression level of the Fas gene. Actin was used as a control. (B) Expression of Fas protein, determined by western blot analysis. Protein extracts were prepared from SCC-VII cells following treatment with $20 \mu \mathrm{g} / \mathrm{ml}$ rTumstatin for the indicated times $(6,9,12,24$ and $48 \mathrm{~h}) . \beta$-actin was used as an internal control. (C) Cell viability was determined by MTT assay. SCC-VII cells were treated for $12 \mathrm{~h}$ with $20 \mu \mathrm{g} / \mathrm{ml} \mathrm{rTumstatin}$ in the presence or absence of neutralizing anti-Fas antibody $(1 \mu \mathrm{g} / \mathrm{ml})$. Data are presented as the mean \pm standard deviation of three experiments. ${ }^{* * * *} \mathrm{P}<0.001 \mathrm{vs}$. control cells. Ctrl, non-treated control cells; rT, recombinant tumstatin-treated SCC-VII cells; rTumstatin, recombinant tumstatin.

A

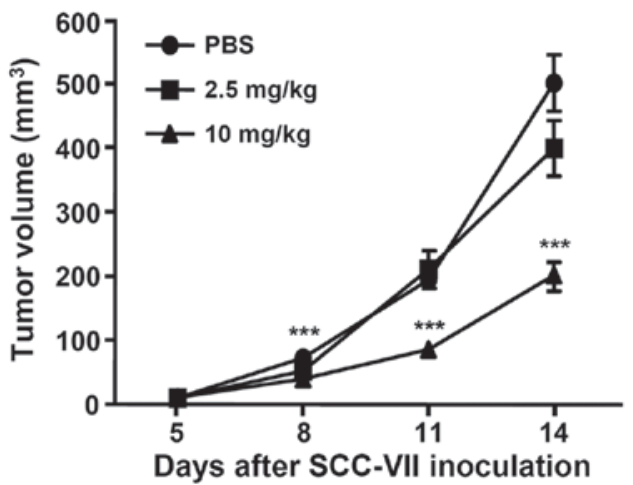

B

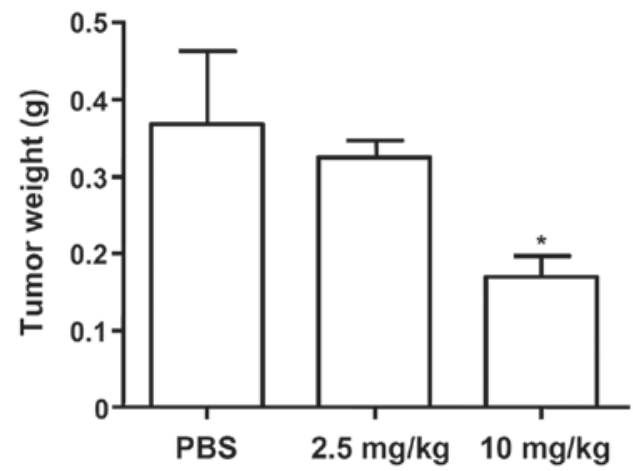

Figure 5. Effect of recombinant tumstatin on tumor growth in an SCC-VII animal model. SCC-VII cells (1x10 ${ }^{6}$ cells in $100 \mu 1$ PBS) were subcutaneously injected into the right flanks of $\mathrm{C} 3 \mathrm{H} / \mathrm{HeJ}$ mice. After the tumor was established (five days; tumor volume $\sim 10 \mathrm{~mm}^{3}$ ), the mice were treated at three-day intervals with peritumoral injections of either recombinant tumstatin ( 2.5 or $10 \mathrm{mg} / \mathrm{kg}$ in PBS) or PBS only (control) for nine days. (A) Tumor volumes were measured with a caliper and are shown as a diagram. (B) Tumor weights subsequent to necropsy, shown as a bar diagram. Data are presented as the mean \pm standard deviation of triplicate experiments. ${ }^{*} \mathrm{P}<0.05$ and ${ }^{* * * *} \mathrm{P}<0.001$, vs. control cells. PBS, phosphate-buffered saline.

increased in the SCC-VII cells treated with recombinant tumstatin compared with that of untreated control cells, based on $\beta$-actin expression that was used as an internal control. The induction of Fas expression by recombinant tumstatin was further confirmed by western blot analysis, which revealed that treatment with recombinant tumstatin increased the protein level expression of Fas (Fig. 4B); following treatment of SCC-VII cells with $20 \mu \mathrm{g} / \mathrm{ml}$ recombinant tumstatin for 24 or $48 \mathrm{~h}$, the expression of Fas protein increased by 2.8- and 3 -fold, respectively, relative to that of control cells. These data indicate that recombinant tumstatin increases the expression of Fas in SCC-VII cells.

Cell viability was determined in SCC-VII cells following treatment with recombinant tumstatin in the presence or absence of anti-Fas antibody (Fig. 4C). The presence of
anti-Fas marginally increased the viability of recombinant tumstatin-treated SCC-VII cells: When SCC-VII cells were treated for $12 \mathrm{~h}$ with $20 \mu \mathrm{g} / \mathrm{ml}$ recombinant tumstatin in the absence of anti-Fas, the cell viability decreased to $56.3 \%$ of that for untreated control cells. Following treatment with $20 \mu \mathrm{g} / \mathrm{ml}$ recombinant tumstatin in the presence of anti-Fas, the cell viability decreased to $77.6 \%$ of that for untreated control cells. Therefore, in anti-Fas-treated SCC-VII cells, the decrease in cell viability due to recombinant tumstatin was diminished by $49 \%(\mathrm{P}=0.0003)$, indicating that anti-Fas attenuated the apoptotic effects of recombinant tumstatin in the SCC-VII cells.

Recombinant tumstatin inhibits tumor growth in an SCC-VII animal model. The antitumor activity of recombinant tumstatin 
was examined in an SCC-VII animal model using $\mathrm{C} 3 \mathrm{H} / \mathrm{HeJ}$ mice. At five days after subcutaneous implantation of SCC-VII cells, the mean tumor volume was $\sim 10 \mathrm{~mm}^{3}$. C3H/HeJ mice were divided into groups and injected with recombinant tumstatin for nine days. No acute side effects, such as body weight loss, hair loss, lethargy or mortality, were observed (data not shown). In the control (PBS-treated) group, the tumors grew rapidly and reached an average volume of $501 \pm 43.9 \mathrm{~mm}^{3}$ (mean \pm SD) on day 14 after inoculation with SCC-VII cells (Fig. 5A). The mean size of the primary tumor in animals treated with 2.5 and $10 \mathrm{mg} / \mathrm{kg}$ recombinant tumstatin was determined to be to 79.6 and $40.3 \%\left(399 \pm 43.6\right.$ and $202 \pm 20.2 \mathrm{~mm}^{3}$, respectively) of that in the control group at 14 days. Similarly, the mean tumor weight for the animals treated with 2.5 and $10 \mathrm{mg} / \mathrm{kg}$ recombinant tumstatin was 88.2 and $46.2 \%$ of that in the control group, respectively (Fig. 5B). Together, these results indicate that recombinant tumstatin inhibited tumor growth in the SCC-VII animal model.

\section{Discussion}

The present study examined the effect of tumstatin on the viability of mouse squamous cell carcinoma SCC-VII cells and investigated the mechanism involved in tumstatin-induced apoptosis. Recombinant tumstatin, expressed and purified from stably transfected D. melanogaster S2 cells (14), was found to inhibit the viability of SCC-VII cells in a dose-dependent manner (Fig. 1) and induce apoptosis, as characterized by confocal microscopic analysis of YO-PRO-1-stained cells (Fig. 2), an increase in the sub-G1 apoptotic cell population (Fig. 3A and B) and DNA fragmentation (Fig. 3C).

Tumstatin combines with an $\alpha_{v} \beta_{3}$ integrin and suppresses the activity of focal adhesion kinase, phosphatidylinositol 3-kinase and protein kinase B, resulting in the inhibition of integrin-induced cap-dependent protein synthesis and suppression of endothelial cell proliferation $(16,17)$. The T7 peptide of tumstatin, a 25 -amino acid region encompassing amino acids 74-98, has been reported to be responsible for the anti-angiogenic activity associated with tumstatin, eventually causing the suppression of tumor growth (18). Tumstatin also exerts direct antitumor activity by suppressing tumor cell proliferation and inducing tumor cell apoptosis. Peptide 19, encompassing amino acids 185-203, is responsible for the antitumor activity of tumstatin (8). In addition, peptide 19 has been demonstrated to inhibit the activation of polymorphonuclear leukocytes (19) and inhibit the proliferation of human gastric cancer SGC-7901 cells and hepatoma HepG2 cells to induce apoptosis (20,21). Furthermore, previous studies have reported that peptide 19 increased the expression of Fas, Fas ligand, and caspase-3 in orthotopic SGC-7901-induced tumor tissues (20) and upregulated the expression of caspase-9, Fas, p53, Bax and Bid in human hepatoma cells (21).

In our preliminary experiments that led to the present study, the expression of apoptosis-associated genes was assessed by microarray analysis using an Agilent mouse cDNA chip and total RNA prepared from tumstatin-treated SCC-VII cells. Expression of the Fas gene increased by 1.73 -fold in the SCC-VII cells following treatment with $20 \mu \mathrm{g} / \mathrm{ml}$ recombinant tumstatin for $12 \mathrm{~h}$ (data not shown). Semi-quantitative RT-PCR and western blot analysis confirmed that treatment with recombinant tumstatin increased the levels of Fas transcript and protein (Fig. 4A and B).
In addition, treatment with anti-Fas increased the viability of SCC-VII cells treated with recombinant tumstatin compared with that of cells treated only with recombinant tumstatin (Fig. 4C). Fas is a death domain-containing member of the tumor necrosis factor receptor superfamily that plays a central role in the physiological regulation of apoptosis (22). The Fas-mediated apoptosis pathway involves the activation of procaspases. In particular, the activation of procaspase- 8 induces the cleavage of the proapoptotic $\mathrm{Bcl}-2$ family member, Bid (23). This triggers the oligomerization of the apoptotic Bcl-2 family members, Bak or Bax, and the release of mitochondrial cytochrome $c$. The released cytochrome $c$ forms an apoptosome with Apaf-1, resulting in the sequential activation of procaspase- 9 and -3 . In our preliminary study, the microarray analysis results revealed that Fas signaling pathway-associated genes, including Fas, caspase-3, caspase-8, caspase-9 and $\mathrm{Bid}$, were upregulated by recombinant tumstatin; by contrast, the antiapoptotic $\mathrm{Bcl}-2$ gene was downregulated (data not shown). Therefore, these results indicate that tumstatin induces apoptosis in SCC-VII cells through the Fas signaling pathway.

In the present study, the antitumor activity of recombinant tumstatin was also investigated in a SCC-VII animal model using $\mathrm{C} 3 \mathrm{H} / \mathrm{HeJ}$ mice. Tumstatin has been reported to suppress the tumor growth of human renal cell carcinoma (786-O cells) and prostate carcinoma (PC-3 cells) in mouse xenograft models $(8,24)$. Tumstatin has also been demonstrated to inhibit tumor growth in malignant melanoma, glioma and subcutaneous glioblastoma animal models (10-12,25). In an orthotopic oral squamous carcinoma AT-84 animal model, treatment with medium containing tumstatin delayed primary tumor growth and lymph node metastasis; however, the effects of tumstatin on suppressing the growth of AT-84-induced tumors were weak compared with tumstatin-free media (13). By contrast, in the present study, recombinant tumstatin effectively reduced the tumor size and weight in the SCC-VII animal model (Fig. 5), indicating that tumstatin exhibits an antitumor activity that suppresses the tumor growth of squamous cell carcinoma cells.

In conclusion, the results of the current study demonstrated that tumstatin induced apoptosis and inhibited proliferation of mouse oral squamous cell carcinoma SCC-VII cells in vitro, and inhibited tumor growth in vivo. Furthermore, the tumstatin-induced apoptosis in SCC-VII cells was found to be mediated by the Fas signaling pathway. These findings implicate tumstatin as a candidate antitumor drug for the treatment of squamous cell carcinomas.

\section{Acknowledgements}

This study was supported by the Basic Science Research Program through the National Research Foundation of Korea, funded by the Ministry of Education, Science and Technology (grant no. NRF-2013RA1A2062398).

\section{References}

1. Koch WM, Stafford E and Bajaj G: Cancer of the oral cavity. Part A: General principles and management. In: Head and neck cancer: A multidisciplinary approach. Harrison LB, Sessions RB, Hong WK (eds). 3rd edition. Lippincott Williams and Wilkins, Philadelphia, PA, pp250-pp265, 2009.

2. Feller L and Lemmer J: Oral squamous cell carcinoma: Epidemiology, clinical presentation and treatment. J Cancer Ther 3: 263-268, 2012. 
3. Raff MC, Barres BA, Burne JF, Coles HS, Ishizaki Y and Jacobson MD: Programmed cell death and the control of cell survival: Lessons from the nervous system. Science 262 : 695-700, 1993.

4. Wyllie AH, Kerr JF and Currie AR: Cell death: The significance of apoptosis. Int Rev Cytol 68: 251-306, 1980.

5. Kaufmann SH and Earnshaw WC: Induction of apoptosis by cancer chemotherapy. Exp Cell Res 256: 42-49, 2000.

6. King KL and Cidlowski JA: Cell cycle regulation and apoptosis. Annu Rev Physiol 60: 601-617, 1998.

7. Boedefeld WM 2nd, Bland KI and Heslin MJ: Recent insights into angiogenesis, apoptosis, invasion and metastasis in colorectal carcinoma. Ann Surg Oncol 10: 839-851, 2003.

8. Maeshima Y, Colorado PC, Torre A, Holthaus KA, Grunkemeyer JA, Ericksen MB, Hopfer H, Xiao Y, Stillman IE and Kalluri R: Distinct antitumor properties of a type IV collagen domain derived from basement membrane. J Biol Chem 275: 21340-21348, 2000.

9. Hamano Y and Kalluri R: Tumstatin, the $\mathrm{NC1}$ domain of $\alpha 3$ chain of type IV collagen, is an endogenous inhibitor of pathological angiogenesis and suppresses tumor growth. Biochem Biophys Res Commun 333: 292-298, 2005.

10. Pasco S, Brassart B, Ramont L, Maquart FX and Monboisse JC: Control of melanoma cell invasion by type IV collagen. Cancer Detect Prev 29: 260-266, 2005.

11. Pasco S, Ramont L, Venteo L, Pluot M, Maquart FX and Monboisse JC: In vivo overexpression of tumstatin domains by tumor cells inhibits their invasive properties in a mouse melanoma model. Exp Cell Res 301: 251-265, 2004.

12. Kawaguchi T, Yamashita Y, Kanamori M, Endersby R, Bankiewicz KS, Baker SJ, Bergers G and Pieper RO: The PTEN/Akt pathway dictates the direct alphaVbeta3-dependent growth-inhibitory action of an active fragment of tumstatin in glioma cells in vitro and in vivo. Cancer Res 66: 11331-11340, 2006.

13. Chung IS, Son YI, Ko YJ, Baek CH, Cho JK and Jeong HS Peritumor injections of purified tumstatin delay tumor growth and lymphatic metastasis in an orthotopic oral squamous cell carcinoma model. Oral Oncol 44: 1118-1126, 2008.

14. Jeon HK, Chang KH, Kim KI and Chung IS: Functional expression of recombinant tumstatin in stably transformed Drosophila melanogaster S2 cells. Biotechnol Lett 25: $185-189,2003$.

15. Alessandri G, Filippeschi S, Sinibaldi P, Mornet F, Passera P, Spreafico F, Cappa PM and Gullino PM: Influence of gangliosides on primary and metastatic neoplastic growth in human and murine cells. Cancer Res 47: 4243-4247, 1987.
16. Maeshima Y, Colorado PC and Kalluri R: Two RGD-independent alpha $v$ beta 3 integrin binding sites on tumstatin regulate distinct anti-tumor properties. J Biol Chem 275: 23745-23750, 2000.

17. Maeshima Y, Sudhakar A, Lively JC, Ueki K, Kharbanda S, Kahn CR, Sonenberg N, Hynes RO and Kalluri R: Tumstatin, an endothelial cell-specific inhibitor of protein synthesis. Science 295: 140-143, 2002.

18. Maeshima Y, Yerramalla UL, Dhanabal M, et al: Extracellular matrix-derived peptide binds to alpha(v)beta (3) integrin and inhibits angiogenesis. J Biol Chem 276: 31959-31968, 2001.

19. Monboisse JC, Garnotel R, Bellon G, Ohno N, Perreau C, Borel JP and Kefalides NA: The alpha 3 chain of type IV collagen prevents activation of human polymorphonuclear leukocytes. J Biol Chem 269: 25475-25482, 1994.

20. Li YJ, Sun LC, He Y, Liu XH, Liu M, Wang QM and Jin XM: The anti-tumor properties of two tumstatin peptide fragments in human gastric carcinoma. Acta Pharmacol Sin 30: 1307-1315, 2009

21. Liu Y, Li J, Xu H, Zhang Y, Liu Y and Liu X: Mitochondria-mediated tumstatin peptide-induced HepG2 cell apoptosis. Int J Mol Med 24: 653-659, 2009.

22. López-Hernández FJ, Ortiz MA and Piedrafita FJ: The extrinsic and intrinsic apoptotic pathways are differentially affected by temperature upstream of mitochondrial damage. Apoptosis 11: 1339-1347, 2006.

23. Yin XM: Signal transduction mediated by Bid, a pro-death Bcl-2 family proteins, connects the death receptor and mitochondria apoptosis pathways. Cell Res 10: 161-167, 2000.

24. Maeshima Y, Manfredi M, Reimer C, Holthaus KA, Hopfer H, Chandamuri BR, Kharbanda S and Kalluri R: Identification of the anti-angiogenic site within vascular basement membrane-derived tumstatin. J Biol Chem 276: 15240-15248, 2001.

25. Oliveira-Ferrer L, Wellbrock J, Bartsch U, Penas EM, Hauschild J, Klokow M, Bokemeyer C, Fiedler W and Schuch G: Combination therapy targeting integrins reduces glioblastoma tumor growth through antiangiogenic and direct antitumor activity and leads to activation of the pro-proliferative prolactin pathway. Mol Cancer 12: 144, 2013. 